\title{
Tipping: An Incentive/Reward for Service?
}

\author{
Michael Lynn, Cornell University \\ Jeffrey Graves, University of Houston
}

Tipping is an interesting, pervasive, and under researched form of consumer behavior. Tips are supposed to be an incentive/reward for good service. However, tipping is a complex behavior motivated by the desires to conform with social norms, compensate for poor service wages, display power/status, avoid the servers' envy and ill will, and express interpersonal attraction. It is possible that these other motives for tipping undermine its role as an incentive/reward. This possibility was examined in two original studies of restaurant tipping. The studies found that tipping is related to consumers' evaluations of service and the dining experience, but that these relationships are weak. This result suggests that tipping is, in part, a reward for good service, but that it may not provide a sufficient incentive for the delivery of good service. Key Words: restaurant tipping, employee motivation, service quality.

\section{Introduction}

"Tipping is a universal language in itself, because we all use tipping to communicate our degree of satisfaction for services we receive."

- The Art of Tipping

"A tip is a gesture of appreciation for service; the percentage of the tip isn't an absolute, so consider the quality of service before deciding on the amount you will leave."

- Charlotte Ford's Book of Modem Manners

"No longer is tipping a reward and not always is it an incentive. It's well known that the word 'tip' derives from an eighteenth-century usage and stands for the words 'To Insure Promptness.' It doesn't always insure any such thing, as we all know. What a tip does insure, we trust, is a living wage for the tippee, and it has become obligatory."

- Good Housekeeping's Book of Today's Etiquette

"Certain tips are obligatory. Tips are a standard part of the income of bell-boys, porters, waiters and beauty-shop employees. It is cheating to skip or skimp tips to them..."

- The Encyclopedia of Etiquette

People often give voluntary payments of money (or tips) to service workers who have served them. These tips are supposed to be an incentive/reward for good service. The intangible and highly customized nature of many services makes it difficult for firms to monitor and control the quality of their service offerings to the public (Shamir, 1984; Zeithaml, Berry \& Parasuraman, 1988). Tipping is a way of enlisting the customer's help in performing these quality control functions. In fact, economists argue that the custom of tipping exists precisely because customers can monitor and reward many 
service inputs more efficiently than can service firms (Bodvarsson \& Gibson, 1994; Hemenway, 1984; Jacob \& Page, 1980).

In order for tipping to function as an incentive/reward for service, consumers must vary the sizes of their tips with their evaluations of the service encounter. One theoretical reason for expecting consumers to do this can be found in equity theory (Walster, Berschei \&Walster, 1973). According to this theory, people are socialized to treat others equitably even when doing so results in some costs to themselves. A relationship is equitable when each of the participant's outcomes from the relationship are proportionate to their inputs to the relationship. There are a number of different mathematical formulas specifying what is meant by this definition of equity. However, when only positive resources are being exchanged, the following formula proposed by Adams (1965) is adequate: $\mathrm{Oa} / \mathrm{la}=\mathrm{Ob} / \mathrm{lb}$. In this formula, $\mathrm{Oa}$ and $\mathrm{Ob}$ refer to person A's and person B's outcome from an exchange, while la and Ib refer to their inputs to the exchange. Since tips and services are inputs and outcomes in exchanges between customers and servers, the equity theory suggests that consumers will seek to maintain equitable relationships with their servers by tipping more for more favorable evaluations of the service.

Although predicted by the equity theory, it is not clear that consumers actually do vary the sizes of their tips with their evaluations of the service encounter. Tipping is a complex behavior with many meanings and motivational bases-it is a norm-driven behavior (Hemenway, 1980; McCarty, et al., 1990), a compensation for poor service wages (Crespi, 1947; Holloway, 1985), a display of status/power (Faber, 1982; Scott, 1916; Shamir, 1984), a payment of protection money against the server's envy and illwill (Carlson, 1977; Foster, 1972), a gift from the customer to the server (Shamir, 1984), and an expression of liking and interpersonal attraction. It is possible that these other aspects of tipping have undermined its role as an incentive/reward for service. This possibility raises an interesting empirical question-is tipping related to consumer's evaluations of the service encounter or not?

Existing research does not permit any firm conclusions about tipping's relationship to service evaluations. Lynn and Grassman (1990) did find a positive relationship between restaurant customers' evaluations of the service encounter and their self-reported tip amounts. However, their study involved a small sample ( $n=103)$ from only one restaurant, which raises a question about the generalizability of their results. Furthermore, numerous other studies have failed to find a significant relationship between tipping and service evaluations (Bodvarsson \& Gibson, 1994; Crusco \& Wetzel, 1984; Lynn, 1988; Lynn \& Latane, 1984; May, 1978), which raises a question about the replicability of Lynn and Grassman's (1990) results. Clearly, there is a need for additional assessments of tipping's relationship to service evaluations. This need is addressed in two original studies reported below. 


\section{Study 1}

Study 1 attempted to replicate Lynn and Grassman's (1990) relationship between tipping and service evaluations. As in the original study, interviewers questioned departing restaurant patrons about their recently concluded dining experiences and tipping behaviors. The data from these interviews permitted an assessment of the generalizability of Lynn and Grassman's (1990) finding to different restaurants and to a different region of the United States, as well as an assessment of its replicability.

\section{Data Source}

\section{Method}

The data for this study was collected at two different chain restaurants-a Bennigan's and an Olive Garden in Houston Texas. The participation rate among those customers approached was $49 \%$ at Bennigans and $81 \%$ at the Olive Garden. This difference in participation rates may be due to the fact that the Bennigan's was situated inside a large shopping mall while the Olive Garden was not. Two hundred twenty-one interviews were completed, but many interviews were excluded from analysis because the respondents ordered only beverages from the restaurant, because they did not answer every question included in the analyses, or because they answered the question about tip size with a percentage figure rather than the monetary figure requested. A total of 161 observations were retained for analysis.

Procedure

Interviewers were recruited from a hospitality service class and were given class credit for their participation. They received questionnaires that contained an approach script, brief instructions, interview questions, places to record the respondent's answers, and places to record other information like the restaurant's name, the date, the number of refusals, etc. Interviewers also received instruction about how to conduct the interviews. They stood outside the restaurants and intercepted customers who were leaving. Upon approaching the customers, the interviewers introduced themselves, indicated that they were university students conducting a study for a hotel and restaurant management class, and asked the customers if they would answer several questions. Those dining parties that agreed to participate were asked to have the person(s) paying the bill answer the questions. W h e $\mathrm{n}$ dining parties indicated that they had separate checks, the people paying those checks were each interviewed andtheir responses were later combined to form one observation per dining party. 
Variables

The participants were asked the following questions.

1. "How many people were in you party?" [Mean=2.52, SD=1.15.]

2. "Did your party have: Appetizers $(\mathrm{Y} / \mathrm{N})$ ? Soups $(\mathrm{Y} / \mathrm{N})$ ? Salads $(\mathrm{Y} / \mathrm{N})$ ? Entrees $(\mathrm{Y} / \mathrm{N})$ ? Desserts $(\mathrm{Y} / \mathrm{N})$ ?" [Yes answers to these questions were assigned a value of 1 and were added together to calculate the number of courses ordered. Mean=2.24, $S D=.94$. J Alcohol $(\mathrm{Y} / \mathrm{N})^{\prime}$

[Yes answers were assigned a value of 1 and no answers were assigned a value of 0 . Sixty-six of 161 respondents $(41 \%)$ ordered alcohol.]

3. "Given a 5-point scale with 1 being poor and 5 being excellent, how would you rate the food on: appearance? portion size? taste? temperature? price?" [These variables were averaged to form an index of satisfaction with the food; Mean=4.23, SD=.64, Coefficient Alpha $=.81$.]

4. "Given a 5-point scale with 1 being poor and 5 being excellent, how would you rate the server on: appearance? knowledge of menu? friendliness? speed of service? attentiveness?" [These variables were averaged to form an index of satisfaction with the service;

Mean=4.19, SD=.94, Coefficient Alpha $=.93$.

5. "Was your server a male or female?" [Tables with female servers were assigned a value of 1 and those with male servers were assigned a value of 0 . Fifty-seven of 161 respondents (45\%) had a female server.]

6. "How many times a year do you eat at: this restaurant? all other full-service restaurants?" [First time patrons of the restaurant were given a value of 1 on the first of these questions. Due to problems with many heavy users, a median split was performed on responses to this question classifying respondents as frequent or infrequent patrons of the restaurant. Seventy-six of 161 respondents (47\%) were classified as frequent patrons.]

7. "How much was your bill?" [Presumably, respondents gave total bill amounts, which would include tax. However, the question was not specific on this point. Mean $=\$ 23.76, S D=12.49$.]

8. "How much money did you tip the server?" [Respondents who answered this question with a percentage amount rather than a monetary amount, as requested, were dropped from the study because we were not confident that the percentage answers were accurate. Mean $=\$ 3.46$, $\mathrm{SD}=1.77$.

After completing the interview and thanking the respondent, interviewers recorded their judgments about the respondent's apparent sex, age, and ethnicity. Age was originally coded as teenager, young-adult, middle-aged, or elderly. However, there were few teenagers and elderly persons 
in the sample, so the teenager and young-adult categories were collapsed $(n=75)$ as were the middle-aged and elderly categories $(n=86)$.Ethnicity was originally coded as White, African American, Asian, Hispanic, or Other. However, there were few minorities in the sample, so this variable was recoded as White $(n=119)$ or Non-White $(n=42)$.

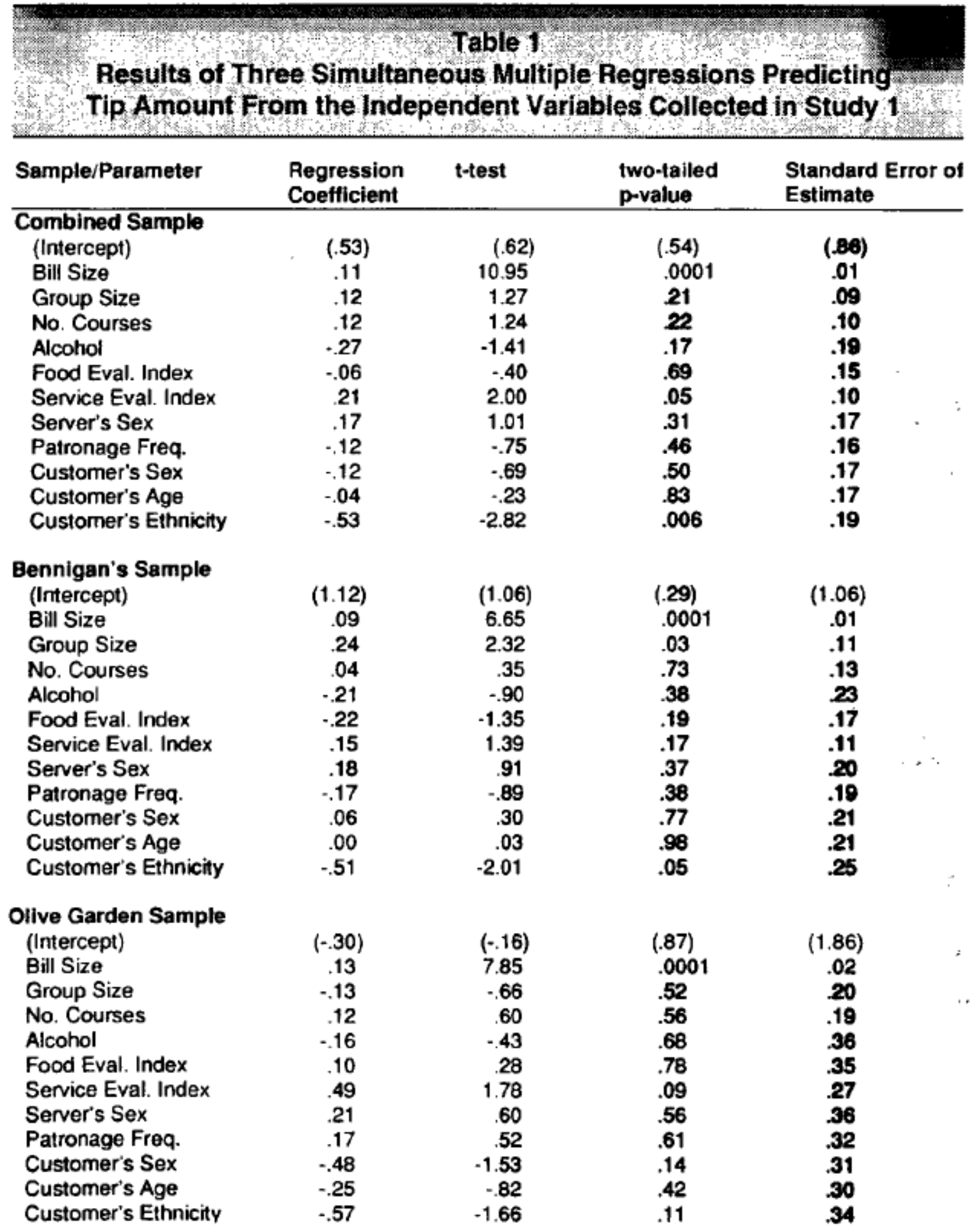


Results

The determinants of tip size were assessed using a simultaneous multiple regression model predicting dollar tip amount from bill size, dining party size, number of courses, alcohol consumption, food evaluation index, service evaluation index, server sex, frequency of patronage, customer sex, customer age ,and customer ethnicity. This model was run on the separate restaurant samples and on the combined sample from both restaurants. The results of these analyses are summarized in Table 1 and are described below.

Bill Size

In the United States, restaurant patrons are expected to tip a percentage (usually 15\%) of their bill amount (Post, 1984). Thus, dollar tip size should be positively related to bill size. Consistent with this expectation, tip size $\mathrm{w}$ a s significantly and positively related to bill size in the combined sample (partial $r=.67, t=10.95, d f=160$, two-tailed $p<.0001$ ) as well as in the separate samples from Bennigan's (partial $r=.59, t=6.65, \mathrm{df}=85$, two-tailed $\mathrm{p}<.0001$ ) and the Olive Garden (partial $\mathrm{r}=.74, \mathrm{t}=7.85, \mathrm{df}=52$, two-tailed $\mathrm{p}<.0001)$. Bill size was the single largest predictor of tip size in this study, suggesting that tipping is primarily a norm-driven behavior.

Service Evaluation Index

Tipping is supposed to be an incentive/reward for the delivery of good service. Consistent with this role, tip size w a s significantly and positively related to the service evaluation index in the combined sample (partial $r=.16, t=2.00, d f=149$, one-tailed $p<.025$ ). This relationship was also positive in the Bennigan's sample (partial $r=.15, \mathrm{t}=.1 .39, \mathrm{df}=85$, one-tailed $\mathrm{p}<.09$ ) and in the Olive Garden sample (partial $r=.24, t=1.78, d f=52$, one-tailed $p<.05$ ). These results suggest that consumers do reward better service with larger tips. However, the observed partial correlations were small, so the role of tipping as a reward accounts for only a small portion of the variance in tip sizes.

\section{Consumer Ethnicity}

Many servers believe that ethnic minorities leave smaller tips than do nonethnic customers (Harris 1995). The results of this study provide s o m e support for this belief. Customer ethnicity was significantly related to tip size in the combined sample (partial $r=.23, t=2.82, d f=149$, two-tailed $p<.006$ ). White respondents left larger tips after controlling for the other independent variables than did nonwhite respondents. This relationship was also observed in the Bennigan's sample (partial $r=.21, t=2.01, d f=85$, 
two-tailed $p<.05$ ) and in the Olive Garden sample (partial $r=.22, t=1.66, d f=52$, two-tailed $p<.11$ ), but was statistically significant only in the larger Bennigan's sample.

Other Variables

Tip size was significantly related to group size in the Bennigan's sample (partial $r=.24, t=2.32$, $d f=85$, two-tailed $p<.03$ ), but no other significant relationships were observed in any of the samples (see Table 1).

\section{Discussion}

This study found that consumers reported tipping larger amounts the more favorably they evaluated the service they received. This relationship was weak (especially in comparison to the relationship between tip amount and bill size), but it replicates a similar finding by Lynn and Grassman (1990) and demonstrates that their finding generalizes to at least two other restaurants and one other region of the United States. Of course, these data are correlational and self-reported, so they do not permit the inference that consumers' service evaluations had a causal impact on the size of their actual tips. The relationship between reported tip size and service evaluations could be the result of confounds (such as the consumer's agreeableness, mood, or desire to appear generous) that might have caused the consumers both to tip more and to evaluate the general dining experience more favorably. However, these alternative explanations would have also predicted a relationship between tip size and the food evaluation index. Contrary to this expectation, reported tip size was unrelated to consumers' evaluations of the food. O $\mathrm{n}$ e simple and plausible explanation for these results is that consumers base their tips on their evaluation of the service but not on their evaluation of the food.

\section{Study 2}

Supplemental analyses of the data from Study 1 suggest that the relationship between tipping and service evaluations was not attributable to consumer dispositions such as mood or generosity. However, one alternative explanation for the study's results cannot be ruled out. The tipping-service relationship observed in Study 1 could be the result of social pressures to report general service evaluations and tip sizes that are consistent with one another. Study 2 was conducted to address this issue. The data for this study were collected in a way that rules out any social pressure on consumers to report tips and service evaluations that are consistent with one another. Restaurant servers routinely ask their customers questions such as: "How is your meal?, "Is everything all right?", or "Is there anything else I can get you?". Customers' responses to these queries vary in both valence and 
effusiveness; some responses $\mathrm{m}$ a y be considered praise and others not. In this study, a waitress judged whether or not her customers' spontaneous remarks and responses to queries like those above constituted praise and that judgment was used as a rough measure of customers' service evaluations. The same waitress also recorded how much her customers tipped her, and this was used as the dependent measure of tipping. By using a server's record of tip size and a naturalistic measurement of customers' service evaluations, the study avoids the impression management demands for consistency that exist when customers are explicitly asked to provide both service evaluations and tip information.

\section{Method}

\section{Data Source}

The data in this study was collected at a Red Lobster restaurant in Columbia, MO. One waitress collected data for each table she served on weeknights after 5:00PM. Although this waitress also worked weekday lunches and weekend dinners, these shifts were too busy to permit data collection. A total of 178 tables were observed during 15 shifts from October 21 to February 23. However, observations of one or more variables were missing for five tables, so only 173 observations were retained for analysis.

Variables

The variables recorded and retained for analysis were:

1. the gender pattern at the table [All female tables were assigned a value of 1 and other tables were assigned a value of 0 . Twenty-seven of 173 tables (16\%) had all female members.];

2. the number of patrons at the table [Mean=2.57, SD=1.46];

3. whether or not children were present at the table [Tables with children were assigned a value of 1 and those without children were assigned a value of 0 . Twenty-two of 173 tables (13\%) included children.];

4. whether or not the waitress thought the patrons were friendly [The waitress recorded her own subjective impressions, assigning friendly tables a value of 1 and less friendly tables a value of 0 . One hundred forty-nine of 173 tables (86\%) were judged to be friendly.];

5. whether or not the waitress thought the patrons voiced praise for some aspect of the dining experience [The waitress recorded her own subjective impressions based on the customers' choice of words and tone of voice. Tables voicing praise were assigned a value of 1 and those not voicing praise were assigned a value of 0 . One hundred seven of 173 tables (62\%) were judged to voice praise.]; 
6. the number of courses (consisting of appetizers, meals, and desserts) the patrons at the table ordered [Mean=1.60, SD=.58];

7. whether or not the table ordered alcohol [Tables ordering alcohol were assigned a value of 1 and those not ordering alcohol were assigned a value of 0 . Ninety-six of 173 tables (55\%) ordered alcohol.];

8. whether or not the table had more than one check [Tables with separate checks were assigned a value of 1 and those with a single check were assigned a value of 0 . Twenty seven of 173 tables (16\%) had separate check.];

9. the total bill amount for the table [Mean $=\$ 32.74, S D=9 . .16]$; and

10. the total tip amount left by the table [Mean $=\$ 3.61, S D=3.10]$.

Procedure

The waitress recorded the above information while she worked each evening. Two additional variables were also recorded-server self-evaluation of service and customer ethnicity-but were dropped from the study because there were too few tables that the server coded as receiving poor service $(n=11)$ and that had ethnic minority group members $(n=5)$. In most (but not all) cases, friendliness and praise were recorded after the final visit to the table and before receipt of the tip. Small babies $w$ h o did not eat anything were not counted when recording gender, group size, and children. Prearranged banquets were excluded from data collection because a $15 \%$ gratuity was automatically added to their bills.

\section{Results}

The determinants of tip size were assessed in a simultaneous multiple regression model predicting dollar tip amount from bill size, dining party size, presence of children, customer friendliness, customer praise of the dining experience, number of courses, alcohol consumption, request for separate checks, and customer sex. This analysis produced significant effects for bill size (partial $r=.41, t=5.72, d f=163$, twotailed $p<.0001$ ) and for customer praise (partial $r=.20, t=2.65, \mathrm{df}=163$, one-tailed $p<.005$ ). As in Study 1, restaurant patrons tipped more the larger their bills and the more favorable their evaluations of the service experience. None of the other variables were significantly related to tip size (see Table 2) .

\section{Discussion}

This study used customers' naturalistic expressions of praise for the dining experience as a measure of their service evaluations. This measure was necessarily flawed, because customers' 
expressions of praise did not always refer specifically to service. However, service is a large component of the dining experience; so satisfaction with service w s certainly a major determinant of customers' expressions of praise even if it was not the only one. Furthermore, researchers have found that customers' evaluations of the dining experience, restaurant atmosphere, and service are highly related to one another (e.g., Crusco \& Wetzel, 1984). This halo effect is likely to be even more pronounced for voluntary expressions of praise, because it is doubtful that customers would praise any aspect of the dining experience if they were not happy with the service too. Thus, praise for som e aspect of the dining experience should be a rough reflection of service evaluations.

At the very least, customers' expressions of praise measured their enjoyment of the dining experience, which is affected by service. If service affects customer enjoyment of the dining experience and enjoyment of the dining experience affects tip size, then tipping should motivate servers to deliver good service. Thus, this measure's relationship to tip size is relevant to tipping's role as an incentive/reward even though it is not a pure measure of service evaluations.

We found that customers $\mathrm{w} h$ o voiced praise for their dining experience during the natural course of the service encounter tipped more than did customers not voicing praise. This relationship cannot be attributed to artificial social pressures or to experimental demand, because the restaurant patrons were unaware that the study was being conducted. Of course, the data is correlational, so firm conclusions about causality are not possible. Confounding variables like consumer's agreeability, mood, or generosity may affect both the expression of praise and the giving of tips, thereby creating a spurious correlation between these two variables. However, these consumer dispositions would be expected to affect perceptions of customer friendliness too, yet this variable was unrelated to tipping. Moreover, this explanation is unlikely account for the results of Study 1 as previously noted. The most plausible and parsimonious explanation for the results of these two studies is that consumers leave larger tips in order to reward servers for good service and an enjoyable dining experience.

\section{General Discussion}

The results of these studies indicate that tipping is positively related to consumers' service evaluations, but that this relationship is weak. Evaluations of the service encounter accounted for only $1-6 \%$ of the variance in bill adjusted tips in these studies. The positive relationship between tipping and 
service replicates Lynn and Grassman's (1990) results and supports the belief that tipping is motivated by a desire to equitably compensate or reward servers. The weakness of this relationship helps to explain the null results that characterize all the other research on this topic. Previous studies may have failed to find significant effects because they did not have enough statistical power to reliably assess such a small effect. The weakness of tipping's relationship to service evaluations also raises serious doubts about the efficacy of tips as incentives. This issue and its managerial implications are discussed below.

\section{The Incentive Value of Tips}

Weak effects, such as those of service variables on tipping, can have meaningful consequences when the effects accumulate overtime. Abelson (1985) found that only $0.3 \%$ of the variance in whether or not a professional baseball player gets a hit when at bat is explained by individual differences in skill. This effect, which is minuscule by traditional standards, produces large and meaningful differences in batting averages when accumulated over many times at bat. A similar argument can be $\mathrm{m}$ a $\mathrm{d}$ e about the relationship between tipping and service. A service delivery effect that accounts for $1-6 \%$ of the variance in bill adjusted tips can have large and meaningful consequences for a server's long-term income when accumulated over many dining parties.

Although the weak effects of service on tipping can have meaningful consequences for servers' long-term incomes, these effects will not motivate servers to deliver good service unless the servers are aware of the relationship. Cohen (1992) defined medium effect sizes as those "likely to be visible to the naked eye of a careful observer" (p.156) and used this label to describe correlations of .30. Since the service-tipping relationships observed in this study and in the existing literature are smaller than correlations of .30, there is some reason to doubt whether or not servers perceive a relationship between their service delivery and the tips they receive. Consistent with this concern are the results of one study in which $47 \%$ of the tipped employees in a five-star hotel reported that there was no direct relationship between the quality of their service and their earnings (Shamir, 1983). Another study of restaurant servers did find a more prevalent belief that tips are related to friendly service (Harris, 1995), but the study did not assess servers' beliefs about the strength of this relationship.

Even if servers do perceive the relationship between service quality and tip size, the weakness of this relationship $\mathrm{m}$ a y lead servers to pursue strategies for increasing tip income that are more effective than, and inconsistent with, providing good service (Carlson, 1977; Mars and Nicod, 1984; Paules, 1991). For example, waiters and waitresses $m$ a y subtly pressure their customers to leave large tips or $m$ a y 
rush their customers in order to turn tables and receive tips from as many dining parties as possible. Thus, the weakness of tipping's relationship to service raises serious doubts about its value as an incentive for the delivery of good service. Tips are, in part, a reward for service, but they may not be a sufficient incentive for service.

\section{Managerial Implications}

The managerial implications of these results are straight forward. First, managers should probably not rely upon tips alone to motivate servers. According to economist, tipping exists because services are difficult for managers to monitor and reward, but are relatively easy for customers to monitor and reward (Bodvarrson \& Gibson, 1994; Hemenway, 1984; Jacob \& Page, 1980). Difficult or not, managers may need to assume a larger, more active role in monitoring and rewarding service employees. If, as these studies suggest, tips provide only a weak incentive, then managers need to supplement customer tipping with other forms of evaluation and incentives. Managers should periodically observe their servers' work, hire undercover evaluators to pose as customers, and/or solicit oral or written feedback from customers. Furthermore, the outcomes of these evaluations should have meaningful consequences for servers. Work schedules, preparation and clean-up assignments, customer seating decisions, and numerous other managerial actions could be used to reward or punish servers as appropriate.

Second, managers should probably not use tips to measure server performance. S o m e restaurants do use tips in this manner. For example, a Mexican restaurant in Houston, TX held a competition among its servers in which the ratio of daily charge tips divided by charge receipts was used to determine the winner. An internal document announcing this competition read:

"This program has been set up to assist you in better serving your guests. It will be monitored by your charge tip averages... Tip averages are the most effective way to measure a server's capabilities and progress within the restaurant."

The results of these studies cast doubt on the claim that tips are the best measure of server performance and suggest that managers need to identify and use other measures.

Finally, managers should probably reconsider their tipping policies. Many consumers dislike tipping (Mills \& Riehle, 1987) and at least some hotels, private clubs and restaurants have adopted "no tipping" policies as a benefit to their customers (Seal, 1995). O $\mathrm{n}$ e argument against this practice is that it eliminates a major incentive for servers to work at pleasing their customers (Frumkin, 1988). However, the results of these studies suggest that the incentive value of tips is likely to be small. As long as any 
lost income is compensated for with higher wages or fixed service charges, the elimination of tipping is unlikely to reduce server motivation. Given this diminution of a major objection to doing away with tipping, managers should at least consider "no tipping" policies. Of course, this does not necessarily mean that tipping should be eliminated; other factors also need to be taken into account when making this decision (Frumkin, 1988). However, one reason for continuing current tipping policies is less compelling in light of the current studies' results.

\section{References}

Abelson, R. P. (1985). A variance explanation paradox: W h e $\mathrm{n}$ a little is a lot. Psychological Bulletin, 97, 129-33.

Adams, J. S. (1965). Inequality in social exchange. In L. Berkowitz (Ed.). Advances in experimental social psychology, (Vol. 2). N e w York: Academic Press.

Berry, L. L (1980). Services marketing is different. Business, 30, 24-28.

Bodvarsson, O. B., \& Gibson, W.A. (1994). Gratuities and customer appraisal of service: Evidence from Minnesota restaurants. Journal of Socio-Economics, 23, 287-302.

Carlson, K. (1977). Reciprocity in the marketplace: Tipping in an urban nightclub. In J.P. Spradley \& D.W. McCurdy (Eds.). Conformity and conflict: Readings in cultural anthropology, (337-347). Boston: Little, Brown and Company.

Cohen, J. (1992). A power primer. Psychological Bulletin, 112, 155-159.

Crespi, L.P. (1947). The implications of tipping in America. The Public Opinion Quarterly, 11, 424-435.

Crusco, A. H., \& Wetzel, C.G. (1984). The Midas touch: The effects of interpersonal touch on restaurant tipping. Personality and Social Psychology Bulletin, 10, 512-517.

Faber, S. (1982). Social class, tipping and alcohol consumption. In C. P. Kottack (Ed.). Researching American culture. Ann Arbor, Ml: University of Michigan Press, 157-162.

Foster, G. M. (1972). The anatomy of envy: A study in symbolic behavior. Current Anthropology, 13, 165202.

Frumkin, P. (1988, July 20). The great tipping debate. Restaurant Business. 113- 120.

Harris, M.B. (1995). Waiters, customers and service: S o m e tips about tipping,. Journal of Applied Social Psychology, 25, 725-744.

Hemenway, D. (1984). Prices and choices: Microeconomic vignettes, Cambridge, MA: Ballinger Publishing Co. 
Holloway, J. C. (1985). Between gratitude and gratuity: Commentary on Shamir. Annals of Tourism Research, 12, 239-242.

Jacob, N., \& Page, A. (1980). Production, information costs, and economic organization: The buyer monitoring case. American Economic Review, 70, 476-478.

Lynn, M. (1988). The effects of alcohol consumption on restaurant tipping. Personality and Social Psychology Bulletin, 14, 87-91.

Lynn, M., \& Grassman , A. (1990). Restaurant tipping: An examination of three 'rational explanations'. Journal of Economic Psychology, 11, 169-181.

Lynn, M., \& Latane, B. (1984). The psychology of restaurant tipping. Journal of Applied Social Psychology, $14,551-563$.

Mars, G., \& Nicod, M. (1984). The world of waiters. London: George Allen and Unwin.

May, J. M. (1978). Tip or treat: A study of factors affecting tipping behavior. Unpublished master's thesis, Loyola University of Chicago.

McCarty, J. A., et al. (1990). Tipping as consumer behavior: A qualitative investigation., In M. E. Goldberg, G. Gorn \& R.W. Pollay (Eds.). Advances in Consumer Research, Vol. 17, (723-728), Provo, UT: Association for Consumer Research.

Mills, S. \& Riehle, H. (1987, October). What customers think about tips vs. service charges. Restaurants USA, 7, 20-22.

Paules, G. F. (1991). Dishing it out: Power and resistance among waitresses in a New Jersey restaurant. Philadelphia: Temple University Press.

Post, E. (1984). Etiquette: A guide to modern manners. New york: Harper \& Row.

Schein, J. E., Jablonski, E.F., \& Wohlfahrt, B.R. (1989). The art of tipping: Customs and controversies. Tippers International.

Scott, W.R. (1916). The itching palm: A study of the habit of tipping in America. Philadelphia: The Penn Publishing Co.

Seal, K. (1995, September 18). No tipping policy highlights hotel's service. Hotel and Motel Management, 210, 8.

Shamir, B. (1983). A note on tipping and employee perceptions and attitudes. Journal of Occupational Psychology, 56, 255-259.

Shamir, B. (1984). Between gratitude and gratuity: An analysis of tipping. Annals of Tourism Research, $11,59-78$. 
Walster, E., Berscheid , E. \& Walster, G.W. (1973). New directions in equity research. Journal of Personality and Social Psychology, 25,551-176.

Zeithaml, V. A., Berry, L. L., \& Parasuraman, A. (1988). Communication and control process in the delivery of service quality. Journal of Marketing, 52; 35-48. 